\title{
Artigo
}

\section{OMBELA: UMA CENA ANCORADA NO IMAGINÁRIO AFRICANO}

\author{
OMBELA: A SCENE ANCHORED \\ IN THE AFRICAN IMAGINARY \\ OMBELA: UNA ESCENA ANCLADA \\ EN LO IMAGINARIO DE ÁFRICA
}

Elton Soares Siqueira

Elton Soares Siqueira Professor adjunto do curso de Teatro/Licenciatura no Departamento de Teoria da Arte e Expressão Artística da Universidade Federal de Pernambuco. 


\section{Resumo}

Este trabalho tem como objetivo central investigar os procedimentos estéticos e metodológicos que, no espetáculo Ombela, do grupo pernambucano O Poste Soluções Luminosas, contribuíram para expressar na cena a ancestralidade africana. Considerando que o grupo em foco pesquisa as contribuições de Mikhail Chekhov e de Eugenio Barba para a realização de um teatro físico, tomaremos os dois autores como referências teóricas de nosso trabalho, a fim de compreender em que medida o teatro físico é, em Ombela, um recurso teórico-metodológico eficaz para a construção de uma cena de matriz africana. A pesquisa contou com anotações feitas a cada apresentação do espetáculo assistida, além de entrevistas com o grupo.

Palavras-chave: Teatro, Ancestralidade, África.

\section{Abstract}

This paper chiefly aims to scrutinize the aesthetic and methodological procedures that, in the performance Ombela, by O Poste Soluções Luminosas, a group from Pernambuco, Brazil, contributed to convey the black-African ancestry on stage. Considering that the group researches the contributions of Mikhail Chekhov and Eugenio Barba to the realization of a physical theater, we will take the two authors as theoretical references for our research, in order to understand to what extent the physical theater is, in Ombela, an effective theoretical-methodological resource for the construction of a scene of black-African matrix. This research was based on notes written during every watched performance, in addition to interviews with the group.

Keywords: Theater, Ancestry, Africa. 


\section{Resumen}

Este estudio tuvo como objetivo investigar los procedimientos estéticos y metodológicos que el espectáculo Ombela, del grupo de Pernambuco O Poste Soluções Luminosas, contribuyó a expresar en escena sobre la ancestralidad africana. Considerando que el referido grupo hace estudios acerca de las contribuciones de Mikhail Chekhov y de Eugenio Barba para la realización de un teatro físico, tenemos en cuenta dos autores como referencias teóricas de nuestro trabajo con la finalidad de comprender en qué medida el teatro físico es, en Ombela, un recurso teórico y metodológico eficaz para la construcción de una escena de matriz africana. Como metodología de investigación fueron utilizados apuntes de todas las presentaciones del espectáculo asistido y de entrevistas con los integrantes del grupo.

Palabras clave: Teatro, Ancestralidad, África.

Pernambuco. Três artistas negros em busca de sua ancestralidade africana. De onde vêm? O que trazem de seu passado ancestral? Qual o ponto de partida desses artistas, que são negros? Para onde caminham? Como entender a diáspora pela qual passaram os negros africanos e que eles mesmos carregam ainda hoje em seu imaginário?

Os artistas: Naná Sodré, Agrinez Melo e Samuel Santos. Eles compõem o grupo de teatro recifense chamado O Poste Soluções Luminosas, que atua desde 2004, primeiramente como grupo de iluminação cênica, ministrando cursos e assessorando tecnicamente diversas companhias e grupos da cidade de Recife. Só em 2008, o grupo amplia seu perfil e passa a montar seus próprios espetáculos, todos eles com uma investigação focada no resgate antropológico da africanidade brasileira, aliada à pesquisa do teatro físico. Assim sendo, a matriz africana é tomada como base de uma ancestralidade corporal e vocal.

Mais especificamente, a pesquisa do grupo procura traçar um paralelo entre as incorporações dos orixás nos terreiros de candomblé e umbanda com os processos de Mikhail Chekhov, Vsevolod Meyerhold, Eugenio Barba 
e Jerzy Grotowski. Para tanto, a dança dos ventos, a antropologia teatral, a biomecânica, a irradiação, as entidades xamânicas e o imaginário dos orixás fazem parte do processo de trabalho d'O Poste.

O primeiro desses trabalhos foi o premiado Cordel do amor sem fim, que estreou em 2009. Seguiram-se a ele outros tantos: Navio negreiro - pelas perspectivas dos orixás (2012), O desconhecido (2014), Anjo negro (2014), A receita (2014), Ombela (2014). Fora esses, o grupo tem sido procurado por artistas que propõem fazer uma imersão teatral, de pesquisa e criação, como foi o caso do espetáculo O açougueiro (2015), dirigido por Samuel Santos, direção de arte d'O Poste e performance do ator Alexandre Guimarães. Em 2014, o grupo inaugura sua sede, concebida como um espaço de fomento cultural e, principalmente, de afirmação das matrizes africanas. O prédio está localizado na Rua da Aurora, bairro da Boa Vista, no Recife.

A história do negro no teatro feito no Brasil ou a história do teatro negro brasileiro ainda está por ser escrita, ou, pelo menos, sistematizada. É com o objetivo de contribuir com o debate, dando maior visibilidade ao negro - não somente na forma como a personagem negra é representada na dramaturgia, mas também registrando e valorizando nele o trabalho de ator/atriz e sua inserção na cena - que focaremos nesta pesquisa a montagem do espetáculo Ombela pelo Poste Soluções Luminosas.

A gênese do espetáculo foi o encontro de Samuel Santos com Manuel Rui, em Recife, no ano de 2010, quando o encenador solicitou um texto ao escritor angolano para encená-lo. Em 2011, Manuel Rui enviou a Samuel Santos um longo poema épico, escrito a partir do mito de Ombela. Na língua umbundu, na qual foi escrito todo o poema de Manuel Rui, ombela significa chuva'.

\section{Aporta no Brasil um texto de forte apelo poético e político}

Antes de enveredarmos pelas águas abundantes do poema Ombela, comecemos por identificar seu autor.

1. Umbundu é uma língua bantu, falada pelos ovimbundus, grupo étnico que constitui, em Angola, um terço de sua população. 
Nascido em 1941, na cidade de Huambo, Angola, Manuel Rui participou do movimento civil pela libertação nacional dede seu país. Vitorioso, o Movimento Popular de Libertação de Angola (MPLA), na voz do então atual primeiro presidente, Agostinho Neto, proclamou a independência do país em 11 de novembro de 1975. Manuel Rui, então, foi convidado a ocupar a função de Ministro da Informação do MPLA no governo de transição estabelecido pelo Acordo do Alvor 3. Também foi o primeiro representante de Angola na Organização da Unidade Africana e nas Nações Unidas. Em seu currículo, foi ainda Diretor do Departamento de Orientação Revolucionária e do Departamento dos Assuntos Estrangeiros do MPLA.

Em seus poemas, contos, crônicas e textos de crítica literária, Manuel Rui busca expressar e valorizar uma cultura de raiz angolana. A forma de apreender a realidade marca uma contraposição à forma eurocêntrica de fazê-lo. Aliás, essa não é uma característica só de Manuel Rui, mas constitui uma característica da literatura africana pós-revoluções de independência. E parece ser do pensamento africano, se considerarmos a perspectiva das epistemologias do Sul, como nos permite ver os artigos contidos na obra organizada por Boaventura de Sousa Santos e Maria Paula Meneses (2010).

Por exemplo, ao contrário do grafocentrismo, que marca as epistemologias do Norte (Europa e América do Norte), a cultura africana de grupos étnicos mais tradicionais tende a se constituir mediante práticas orais, que constroem, endossam e perpetuam saberes: as oraturas. No sítio da Lusofonia, lê-se que a oratura

constitui a expressão de uma sociedade não alfabetizada, mas também e sobretudo de uma sociedade fortemente gregária que procura e encontra na convivência e na palavra um prazer lúdico, a comunicação didáctica e o gosto de viver.

[...] as histórias costumam aparecer entre adivinhas, ditos, passadas, provérbios e cantigas2.

O tempo e o espaço se dilatam e assumem dimensões para além da lógica formal. Funda-se uma outra lógica, pautada numa realidade que é significada por crenças, cazumbis (espíritos), "que comanda as chuvas, os rios,

2. Disponível em: <https://goo.gl/32KxMb>. Acesso em: 15 abr. 2017. 
as atividades humanas e a própria noção ontológica do homem-sujeito com valor de totalidade, intrínseco em si mesmo, longe do homem-objecto" da cultura eurocêntrica (GALVÃO, 2010, p. 4).

Compreende-se, assim, a emergência e a valorização das oraturas como literaturas do saber tradicional num momento histórico em que as nações recém-independentes se encontram num processo de reconstrução de suas identidades, as quais foram maceradas e fragmentadas pelas respectivas políticas de colonização e pelo mediatismo da globalização. Podemos observar esse traço estilístico e expressivo tanto na literatura como também no teatro produzidos nesses países ${ }^{3}$.

O poema épico que Manuel Rui escreveu a pedido do grupo O Poste Soluções Luminosas, Ombela, ainda não publicado, é constituído de vinte cantos, ou, como o autor nomeia, Vinte Palavras. Manuel Rui escreve-o em duas línguas, português e umbundu, para dar voz ao mito de Ombela, deusa da chuva e das águas. Ao mesmo tempo em que o poeta constrói imagens líricas de forte impacto e significado para a cultura angolana tradicional, imprime em seus versos a denúncia da violência colonial, responsável pela morte de muitos homens e mulheres.

Ombela é chuva, ameaça de chuva (ocituto), primeira chuva (ombela lyombela), chuva fina (olume), chuva miudinha (okalusulumila), chuva torrencial (epapwilo), chuva em abundância (apengu), chuva acompanhada de trovão (elilimilambela), falta de chuva (ocitenha), chuva que dura o dia todo (ulembi), chuva acompanhada de sol (epengupengu), chuva abundante mas passageira (etande). Ao surgirem no poema, cada um desses movimentos vem acompanhado de um estado anímico da deusa da chuva.

O erotismo é flagrante nos versos de Manuel Rui, deste seu Ombela. Se a água fertiliza, a chuva é "vagina de água", "útero matinal parindo estrela [...] marida do céu". É da voz de Ombela que ouvimos, como ecos arquetípicos de um sagrado feminino: "Eu é que abro tudo e o vento é que pode ser/calado e falar quando eu quiser porque eu dou banho ao vento/todo nu com as minhas mãos de mulher a minha boca a minha/língua conheço o corpo todo do vento

3. Refiro-me aos países africanos de língua oficial portuguesa (Palop), os quais estão ao meu alcance: Angola, Cabo Verde, Guiné-Bissau, Guiné Equatorial, Moçambique e São Tomé e Príncipe. 
e sua intimidade"; "Sou eu própria chuva fêmea. Uma/boca de beijo. Meu marido céu que desengravido".

Ombela também recupera as vozes dos angolanos silenciados, "pensamentos imaginados tão de longínquos mais/que o fim do traço do mar com a terra e as vozes/que se desacorrentaram sem ser para sempre o infinito." Como uma feiticeira, é a chuva que "amarra uma família/à volta de um fogo e fumo para as falas se cruzarem bem/com relâmpagos distantes esquecidos do som emudecido/por detrás da pedra do eco Huambo Kalunga". É a voz que recupera nas falas das famílias os ecos de Huambo Kalunga, personagem angolana importante na região do Planalto Central, nos idos do século XVII, que se torna sebo (líder) no local que recebeu seu nome, fazendo jus a personalidades da história e cultura angolanas.

A denúncia social também é encontrada nos seguintes versos: "Eu sou a chuva em cima das lavras e dos cemitérios da guerra/que me escutam em paz assustada/filha do relâmpago e da trovoada que racham o céu/e engrandecem as pedras grandes da Caála onde me quiseram/matar com pólvora”.

Sabemos que foi em Caála, município de Huambo, que se deu a chegada do caminho de ferro, em 1912, com a exploração colonial da sociedade local pelo (ab)uso de sua força de trabalho, custando-lhe algumas mortes. Ombela pede que "contem/só cada gota contem as minhas gotas para que eu possa cair/sempre e nunca um dia a morte mate a palavra". A palavra resiste e se afirma como testemunho de toda a violência pela qual passou o povo angolano enquanto era colônia.

Mas a denúncia não vem carregada de ressentimentos. Ao mesmo tempo em que reconhece as agruras de seu povo, Ombela assume uma postura digna ao não recusar água a seus algozes. O tempo de guerras e opressões já é passado. E a água da chuva vem varrer os escombros de uma cultura destroçada para arrancar da terra os bichos e os mortos que vivem perto das árvores amigas, para celebrar sua honradez e fertilizar o solo para a retomada cultural. "Uma água/que não cheira/a petróleo/nem a dólares/nem a morte", pois é "mulher de água que também sabe tecer lençóis/para os namorados que fazem amor com a minha música/as faíscas/e os trovões". E com esses versos Manuel Rui fecha seu poema, apontando para um futuro em construção e em reconstrução. 


\section{Teatro físico e ancestralidade africana}

Teatro físico constitui uma categoria difusa e polêmica. Nas três últimas décadas do século $\mathrm{XX}$, o termo passou a ocupar o espaço dos principais debates sobre a cena contemporânea, definindo, a despeito de sua flutuação semântica, uma série de atividades cênicas, no cruzamento entre dança, teatro, mímica e circo, que enfatiza a materialidade do evento no corpo do artista. Subentende-se, a partir do conceito, que se trata de uma ação sobre a fisicalidade, um foco sobre a disposição do corpo do artista em função de uma dada teatralidade. Cabe, nesse debate, uma pergunta: existe alguma cena que prescinda da corporeidade do artista/ator?

O espaço deste artigo não comporta uma discussão dessa ordem. Deixarei, portanto, para fazê-la numa outra oportunidade. Por ora, utilizarei esse conceito "guarda-chuva" sempre que estiver me referindo às contribuições teóricas de Mikhail Chekhov e de Eugenio Barba, mesmo que nenhum deles tenha sequer usado o termo com a carga semântica que nossas disciplinas acadêmicas costumam dar a ele.

O grupo O Poste Soluções Luminosas assume que sua pesquisa vem se baseando no teatro físico, particularmente, nos postulados de Mikhail Chekhov e de Eugenio Barba. Os artistas se identificam com esses autores e encontraram neles um modo de fazer teatro, via trabalho de ator/atriz, que atende a suas expectativas como sujeitos da cena e como sujeitos de teatro. Que postulados são esses? Vejamos alguns deles.

Em seu livro Para o ator, editado em 1953, Mikhail Chekhov (1891-1955) apresenta alguns dos princípios que nortearam seu trabalho como ator $\mathrm{e}$ como mestre. Dentre os pilares de seu método, encontramos o trabalho com a concentração, com a imaginação, com as qualidades de movimento; as noções de ensemble, atmosferas subjetivas e objetivas, os "Quatro Irmãos" (desenvoltura/forma/beleza/inteireza). O corpo do ator é trabalhado a partir de seus centros imaginários, do gesto psicológico, na perspectiva do irradiar/receber. Para além desses aspectos, um dos legados especiais do pensamento e prática de Chekhov corresponde ao desafio de nos manter conectados à nossa autenticidade, apesar dos diversos estímulos externos a que está sujeito nosso corpo. 
Eugenio Barba (1936-), por sua vez, trabalha com categorias que chama de "princípios-que-retornam", os quais são, no corpo do ator: o cotidiano e o extracotidiano; o equilíbrio em ação; a dança das oposições; a incoerência coerente e virtude da omissão; a equivalência; e um corpo decidido. Barba se refere a esses princípios como "bons conselhos" aos atores. Cabe à antropologia teatral rastrear esses "princípios-que-retornam" e proporcionar a dilatação da energia do ator, possibilitando-lhe estar presente inteiramente em cena; daí o trabalho atento e exaustivo com a pré-expressividade.

Em entrevista feita para este trabalho, Naná Sodré explica o que o grupo toma desses autores como princípios norteadores do trabalho atoral. Nos processos de ensaio, procuram alcançar os pontos energéticos do corpo de cada ator/atriz. Na concepção de todos, trata-se de pontos de ancoramento, aterramento; são possibilidades vocais e possibilidades do corpo como um todo. $O$ método lhes permite terem de si um conhecimento mais justo, de forma que possam se aperceber, passando a sentir o corpo da pele para dentro, para, só assim, poder expressar. Mais do que uma vivência psicológica das personagens, todo o processo consiste num trabalho que exige muita imaginação e controle das energias no uso das ações pré-expressivas e expressivas. Daí experimentar as diversas possibilidades do corpo. Em verdade, O Poste se vale dessas técnicas para o exercício diário do ator/atriz. Como se deu, então, o processo de criação do espetáculo Ombela? Passemos a analisá-lo.

Conforme já dito, o grupo investiga o corpo ancestral na cena contemporânea, em busca de uma criação cênica de matriz africana. Com relação ao trabalho com Ombela, em particular, o grupo tinha muito medo de adentrar pelo universo africano e fazer um desserviço às lutas pela afirmação das africanidades, seja caindo no estereótipo, seja ferindo princípios de algum ritual por eles desconhecidos. Com o texto de Manuel Rui em mãos, depararam com um devir desconhecido. Para suprir suas carências, eles foram assessorados por uma antropóloga, a profa. Danielle Rocha Pitta, que foi responsável por situar o elenco no mundo, nas palavras de Naná Sodré. Foram-Ihes transmitidas informações bastante relevantes quanto às culturas africanas, como o compartilhamento da experiência, o respeito aos mais velhos, a relação com a terra, além de elementos constitutivos do universo imaginário dos africanos. 
Como Ombela significa chuva e todo o texto torna a chuva em deusa, princípio das águas, o grupo aprofundou sua pesquisa sobre o imaginário da água. A partir do arquétipo, os artistas/pesquisadores se centraram nos três temas dominantes: fonte de vida, meio de purificação e centro de regenerescência. Depararam com a dimensão feminina subjacente ao imaginário da água. Enquanto se apropriavam do saber antropológico, trabalhavam na sala de ensaio esse saber aplicado ao corpo, a partir das técnicas já elencadas do teatro físico.

O diretor, Samuel Santos, ainda não satisfeito, propôs às duas atrizes uma pesquisa das religiões de matriz africana, algo não mencionado no texto de Manuel Rui. Do elenco, ele e Naná Sodré são da umbanda; Agrinez Melo, do candomblé. A proposta foi adentrar nesses espaços para estudar o corpo das pessoas que nos rituais recebem entidades e orixás. Foi quando decidiram visitar o terreiro da Mãe Amara, na região metropolitana de Recife. Lá, fizeram descobertas espirituais riquíssimas que muito vieram a contribuir para a concepção cênica do espetáculo que estavam por montar. Por uma questão ética, tais descobertas ficaram sob sigilo, em respeito ao terreiro que os acolheu.

Dessa experiência, chegaram a dois orixás que tomaram como inspiração para o jogo cênico: Oxum e lemanjá. Ambas são divindades das águas do rio, constando que lemanjá, conforme o mito, é filha de Olóòkun, deus (ou deusa) do mar, daí seu domínio se estender também às águas do mar. No espetáculo Ombela, a deusa da chuva presente no texto de Manuel Rui se desdobra, assim, nas duas divindades femininas da nação iorubá, Oxum e lemanjá. Com as técnicas do teatro físico, cada atriz passou a aprofundar, portanto, a pesquisa de suas respectivas divindades. O eixo conceitual da cena estava, pois, traçado.

O espetáculo foi concebido, primeiramente, para o espaço próprio do grupo. As paredes do pequeno espaço foram revestidas de pallets, a fim de acentuar a rusticidade e aproximar o universo da cena ao universo rústico de um terreiro. O cenário é composto por uma estrutura circular, ladeada de canaletas, por onde escorre a água que sai de uma pequena bica ou vem dos alguidás e das cabaças presentes em cena. O conceito do cenário é a circularidade, simbolizando a perfeição, a homogeneidade, a ausência de distinção ou de divisão. Por não ter começo nem fim, nem variações, o círculo simboliza 
o tempo. Esse conceito cenográfico se baseia em alguns elementos concretos: a gira é circular, o terreiro é circular, os rituais são circulares - todos num mesmo nível. O espetáculo, assim, gerava uma atmosfera de intimidade; fazia que os espectadores ficassem muito próximos uns aos outros e muito próximos às atrizes, chegando a receber respingos de água no rosto.

Em cena, as atrizes apresentavam-se seminuas, caracterizadas pelos seus respectivos orixás. Ora se cobriam de colares e pedras, ora lançavam mão de indumentárias inspiradas nos diversos rituais africanos. O corpo sem maquiagem é natureza, essência. Duas atrizes, dois orixás femininos ocupando o centro de um círculo. O jogo de luz explorou as cores dos dois orixás: amarelo (Oxum) e azul (lemanjá). No espaço em que se encontravam, elas cantavam, recitavam e dramatizavam o texto de Manuel Rui, ora em umbundu, ora em português, carregando no corpo e no movimento o erotismo que é tão forte no poema, como já vimos. Destaque seja feito à música composta por Isaar, cantora, compositora e instrumentista negra pernambucana.

O público, nas apresentações em que estive presente, se envolveu profundamente com o ritual apresentado, chegando a participar dele, sobretudo depois que as ombelas (é assim que as atrizes se referem a suas personagens) ofereciam aos espectadores numa cuia uma aguardente forte, permitindo que o corpo, a mente e o espírito dos espectadores se dilatassem.

O intento se realizou.

\section{Considerações finais}

Ombela constitui, sem dúvida, um marco na cena teatral recifense. $O$ Poste Soluções Luminosas é, no momento, o único grupo oficial em Recife formado por atores negros em busca de um teatro negro de matrizes africanas. Com o espetáculo analisado, O Poste avança em suas pesquisas sobre a ancestralidade africana na cena teatral, a começar pela dramaturgia, escrita por um angolano, Manuel Rui, a pedido do grupo pernambucano. Como vimos, o texto, escrito em umbundu e em português, simultaneamente, trabaIha com mitos angolanos e fatos históricos de uma Angola pós-independência. O empenho em recuperar e afirmar a identidade cultural do povo angolano é flagrante na literatura de Manuel Rui. 
Também percebemos no teatro d'O Poste um empenho em se apropriar, num trabalho antropológico e quase arqueológico, das matrizes africanas capazes de reconstituir uma identidade do povo africano, macerada pelo movimento diaspórico, a fim de compreender o homem afrodescendente na sociedade brasileira contemporânea, ainda fortemente marcada por uma história de colonização que se faz presente, a despeito de o país já ter conquistado oficialmente sua independência há quase dois séculos. Uma das marcas sutis dessa colonização corresponde ao legado cultural que recebemos da Europa que tomamos como verdade irrefutável. Por exemplo, a formação dos nossos atores passa, necessariamente, por personalidades ilustres do universo europeu. Mikhail Chekhov e Eugenio Barba são duas dessas personalidades e, inegavelmente, suas contribuições para o teatro são riquíssimas. Utilizá-los como paradigmas metodológicos para o trabalho do ator, como faz o grupo $O$ Poste, certamente possibilita-o chegar a resultados estéticos satisfatórios. $O$ diferencial do grupo está nessa miscigenação antropofágica de ideias e culturas europeias com ideias e culturas de matrizes africanas. Os resultados estéticos satisfatórios refletem, portanto, o diálogo proveitoso dessas epistemologias muitas vezes conflitantes.

\section{Referências bibliográficas}

BARBA, E.; SAVARESE, N. A arte secreta do ator: um dicionário de antropologia teatral. São Paulo: É Realizações, 2012.

CHEKHOV, M. Para o ator. São Paulo: WMF Martins Fontes, 2003.

GALVÃO, L. M. A criatividade expressiva na obra de Manuel Rui. In: COLÓQUIO DA LUSOFONIA, 14., 2010, Bragança. Anais... Bragança: Lusofonia, 2010. Disponível em: <https://goo.gl/AZKsCy>. Acesso em: 26 jul. 2017.

PRANDI, R. Mitologia dos orixás. São Paulo: Companhia das Letras, 2001.

SANTOS, B. S.; MENESES, M. P. (orgs.). Epistemologias do Sul. São Paulo: Cortez, 2010.

VERGER, P. F. Orixás: os deuses iorubás na África e no Novo Mundo. Salvador: Corrupio, 2002.

Recebido em 24/04/2017

Aprovado em 10/06/2017

Publicado em 05/09/2017 